\title{
Clinicopathological variables of sporadic schwannomas of peripheral nerve in 291 patients and expression of biologically relevant markers
}

\author{
Eric D. Young, BS, ${ }^{1}$ Davis Ingram, BS, ${ }^{2,6}$ William Metcalf-Doetsch, MD, ${ }^{7}$ Dilshad Khan, MD, ${ }^{8}$ \\ Ghadah AI Sannaa, MD, ${ }^{3,6}$ Francois Le Loarer, MD, PhD, ${ }^{9}$ Alexander J. F. Lazar, MD, PhD, ${ }^{3,6}$ \\ John Slopis, MD, ${ }^{4}$ Keila E. Torres, MD, PhD, ${ }^{2,6}$ Dina Lev, MD, ${ }^{10}$ Raphael E. Pollock, MD, PhD, ${ }^{11}$ and \\ Ian E. McCutcheon, MD
}

\begin{abstract}
1Department of Cancer Biology, University of Kansas Medical Center, Andover, Kansas; Departments of ${ }^{2}$ Surgical Oncology, ${ }^{3}$ Pathology and Laboratory Medicine, ${ }^{4}$ Neuro-Oncology, and ${ }^{5}$ Neurosurgery and ${ }^{6}$ The Sarcoma Research Center, University of Texas MD Anderson Cancer Center, Houston, Texas; ' Department of Neurosurgery, Northwestern University, Chicago, Illinois; ${ }^{8}$ Department of Internal Medicine, University of Toledo Medical Center, Toledo, Ohio; 'Department of Pathology, Centre Leon Berard, Lyon, France; ${ }^{10}$ Department of Surgery, Sheba Medical Center, Israel; and ${ }^{11}$ Department of Surgery, The Ohio State University, Columbus, Ohio
\end{abstract}

OBJECTIVE While sporadic peripheral schwannomas (SPSs) are generally well treated with surgery, their biology is not well understood. Consequently, treatment options are limited. The aim of this study was to provide a comprehensive description of SPS. The authors describe clinicopathological features and treatment outcomes of patients harboring these tumors, and they assess expression of biomarkers using a clinically annotated tissue microarray. Together, these data give new insight into the biology and management of SPS.

METHODS Patients presenting with a primary SPS between 1993 and 2011 ( $n=291)$ were selected from an institutional registry to construct a clinical database. All patients underwent follow-up, and short- and long-term outcomes were assessed. Expression of relevant biomarkers was assessed using a new tissue microarray $(n=121)$.

RESULTS SPSs were generally large (mean $5.5 \mathrm{~cm}$ ) and frequently painful at presentation $(55 \%)$. Most patients were treated with surgery $(80 \%)$, the majority of whom experienced complete resolution $(52 \%)$ or improvement $(18 \%)$ of their symptoms. Tumors that were completely resected (85\%) did not recur. Some patients experienced short-term (16\%) and long-term (4\%) complications postoperatively. Schwannomas expressed higher levels of platelet-derived growth factor receptor- $\beta$ (2.1) than malignant peripheral nerve sheath tumors (MPNSTs) $(1.5, p=0.004)$ and neurofibromas $(1.33, p$ $=0.007)$. Expression of human epidermal growth factor receptor -2 was greater in SPSs (0.91) than in MPNSTs $(0.33$, $p=0.002)$ and neurofibromas $(0.33, p=0.026)$. Epidermal growth factor receptor was expressed in far fewer SPS cells $(10 \%)$ than in MPNSTs $(58 \%, p<0.0001)$ or neurofibromas $(37 \%, p=0.007)$. SPSs more frequently expressed cytoplasmic survivin ( $66 \%$ of tumor cells) than normal nerve ( $46 \%$ of cells), but SPS expressed nuclear survivin in fewer tumor cells than in MPNSTs (24\% and $50 \%$, respectively; $p=0.018)$.

CONCLUSIONS Complete resection is curative for SPS. Left untreated, however, these tumors can cause significant morbidity, and not all patients are candidates for resection. SPSs express a pattern of biomarkers consistent with the dysregulation of the tumor suppressor merlin observed in neurofibromatosis Type 2-associated schwannomas, suggesting a shared etiology. This SPS pattern is distinct from that of other tumors of the peripheral nerve sheath.

https://thejns.org/doi/abs/10.3171/2017.2.JNS153004

KEY WORDS sporadic schwannoma; peripheral nerve; clinical variables; tissue microarray; biomarker expression; oncology

\footnotetext{
ABBREVIATIONS EGFR = epidermal growth factor receptor; HER = human epidermal growth factor receptor-2; MPST = malignant peripheral nerve sheath tumor; NF2 $=$ neurofibromatosis Type $2 ;$ PDGFR- $\beta=$ platelet-derived growth factor receptor $-\beta ;$ RTK = receptor tyrosine kinase; SPS = sporadic peripheral schwannoma; TMA = tissue microarray.
}

SUBMITTED December 23, 2015. ACCEPTED February 15, 2017.

INCLUDE WHEN CITING Published online September 8, 2017; DOI: 10.3171/2017.2.JNS153004. 
$\mathrm{T}$ HE intricate histological features of schwannomas were first described more than 100 years $\operatorname{ago}^{26}$ and were later found to arise from Schwann cells of the peripheral nerve sheath. ${ }^{18}$ Schwannomas occur most frequently as a single, sporadic lesion. ${ }^{13}$ They are considered benign tumors as demonstrated by their generally low proliferative potential, ${ }^{1}$ their frequently well-circumscribed gross appearance, ${ }^{29}$ and the fact that malignant transformation is exceedingly rare. ${ }^{32}$ However, deep-seated tumors and those intimately associated with critical vascular, neural, and other anatomical structures can cause significant morbidity due to mass effect or erosion of adjacent bone. ${ }^{30}$ Such situations present challenges in resection, ${ }^{24}$ which is currently the best therapeutic option. ${ }^{17}$ The slow growth rate of sporadic peripheral schwannomas (SPSs) renders them generally unresponsive to conventional chemotherapy, ${ }^{14}$ suggesting a need for new treatment options, particularly for patients who are not surgical candidates.

Given these challenges, we sought to elucidate the biology of SPS. Loss or dysfunction of the known tumor suppressor gene $N F 2$ on $22 \mathrm{q} 12.2^{25}$ drives tumorigenesis of schwannomas arising in the hereditary cancer syndrome neurofibromatosis Type 2 (NF2). NF2 encodes the protein merlin, which mediates contact inhibition ${ }^{7}$ by linking a cell's physical surroundings and its mitotic activity. ${ }^{33}$ Merlin also restrains cell proliferation by negatively regulating several receptor tyrosine kinases (RTKs), including platelet-derived growth factor receptor- $\beta$ (PDGFR- $\beta$ ), human epidermal growth factor receptor-2 (HER-2), and epidermal growth factor receptor (EGFR). ${ }^{4}$ Interestingly, loss of heterozygosity in chromosome 22 where merlin is located has been demonstrated in SPS,11 providing evidence for similar pathogenesis in sporadic tumors and their congenital counterparts. Thus, we hypothesized that if similar mechanisms drive sporadic schwannoma growth, we might be able to detect these expression patterns in tumor samples obtained in humans.
To characterize the biology of these tumors, we constructed a clinically annotated tissue microarray (TMA) and used it to assess biomarker expression. We also constructed a clinical database of patients with primary SPS and gathered their clinical presentation, treatment, and outcome information. Together, these new resources provide an informative vignette characterizing the morbidity of SPS both in situ and as sequelae to their resection.

\section{Methods}

\section{Review of the Literature}

We reviewed tissue-based studies of SPS from the literature containing at least 10 patients with follow-up. From these, only tumors that met the following conditions were included: 1) The sample was diagnosed definitively by histological analysis as a schwannoma (vs malignant schwannoma, malignant peripheral nerve sheath tumor [MPNST], neurofibroma, or other peripheral nerve sheath tumor). 2) The sample was sporadic and did not occur in the context of a congenital neurocutaneous syndrome (e.g., NF2, schwannomatosis). 3) The tumor was peripherally located (vs intracranial, or associated with cranial nerves). The clinicopathological features of these tumors were compared with those in the present series (Table 1).

\section{Clinical Database}

Clinical data were collected and analyzed with the approval of the institutional review board at the University of Texas MD Anderson Cancer Center. Patients treated for SPS at University of Texas MD Anderson Cancer Center from January 1, 1993, through December 31, 2011, were selected from the pathology archives and institutional tumor registry databases. Patients with a diagnosis of a single schwannoma (neurilemmoma) arising from a peripheral nerve (including spinal nerve roots) were included in the database, as were histological variants such as cellular schwannoma, plexiform schwannoma, and ancient

TABLE 1. Literature review of clinicopathological data for patients with sporadic schwannomas arising in the peripheral nerves

\begin{tabular}{|c|c|c|c|c|c|c|c|}
\hline Authors \& Year & No. of Pts & Sex & Age Range, Yrs ${ }^{*}$ & Tumor Size, $\mathrm{cm}^{*}$ & No. w/ FU & FU Range, Yrs* & Recurrence (\%) \\
\hline Stout, 1935 & 46 & $26 \mathrm{~F}, 20 \mathrm{M}$ & $19-68(39.3)$ & $1-7.5(3.2)$ & 23 & $0.25-14(2.9)$ & $0(0.0)$ \\
\hline Ackerman \& Taylor, 1951 & 19 & $13 \mathrm{~F}, 6 \mathrm{M}$ & $19-66(44.6)$ & $3.5-20(9.3)$ & 16 & $0.3-8(3.3)$ & $0(0.0) \dagger$ \\
\hline Woodruff et al., 1981 & 13 & $6 \mathrm{~F}, 7 \mathrm{M}$ & $25-71(49.1)$ & $2.7-11(5.7)$ & 8 & $0.167-10(2.58)$ & $0(0.0) \ddagger$ \\
\hline Fletcher et al., 1987 & 16 & $9 \mathrm{~F}, 7 \mathrm{M}$ & $17-73(41.9)$ & NA & 13 & $2-32(15.1)$ & $0(0.0) \S$ \\
\hline Lodding et al., 1990 & 29 & $21 \mathrm{~F}, 8 \mathrm{M}$ & 15-79 (median 55) & 2-12 (median 6.0) & 28 & $0.25-19.5$ (median 7) & $0(0.0)$ \\
\hline White et al., 1990 & $57 \pi$ & $35 \mathrm{~F}, 22 \mathrm{M}$ & $1.3-81(44.0)$ & $1-19.5(6.2)$ & 49 & $1-24(6)$ & $3(6.1)$ \\
\hline Agaram et al., 2005 & 23 & $14 \mathrm{~F}, 9 \mathrm{M}$ & $0.4-67(28.8)$ & NA & 6 & $1.1-10.0$ (median 2.0) & $3(50.0)$ \\
\hline Strauss et al., 2011 & 28 & $21 \mathrm{~F}, 7 \mathrm{M}$ & NA (median 47) & 5-23 (median 9) & 28 & NA (median 3.25) & $0(0.0)^{* *}$ \\
\hline Voltaggio et al., 2012 & 51 & $40 \mathrm{~F}, 11 \mathrm{M}$ & $29-90(58)$ & $1-10.5(5.1)$ & 41 & $1-34.9(11.5)$ & $0(0.0)$ \\
\hline Current study & 291 & $153 \mathrm{~F}, 138 \mathrm{M}$ & $7-89(49.7)$ & $0.3-26(5.5)$ & 291 & $0.1-18.9(4.0)$ & $0(0.0)$ \\
\hline
\end{tabular}

$\mathrm{FU}=$ follow-up; NA = not available, Pts = patients

* Values in parentheses are means unless stated otherwise.

$\dagger$ There was progression of residual disease after incomplete excision in 1 patient $(5.3 \%)$.

$\ddagger$ Residual tumor was observed in 2 patients who received subtotal resection.

$\S$ There was progression of residual disease after incomplete excision with need for repeated excisions in 1 patient (6.25\%).

If Series includes 15 patients from Woodruff et al., 1981 and 1983.

** No progression of residual disease in 3 subtotally resected tumors. 
schwannoma. Patients with other benign (e.g., neurofibroma and neuroma) and malignant (e.g., MPNST, malignant schwannoma, and psammomatous melanotic schwannoma) nerve sheath tumors were excluded. Schwannomas arising from the cranial nerves were not included in the data set in order to exclude potential cases of NF2. Only patients with at least 30 days of follow-up were included. Demographic, disease-specific, tumor-specific, and follow-up variables were analyzed. Progression of disease was defined as an increase in tumor size as detected by MRI, with both T1-weighted postcontrast and T2-weighted images reviewed in all 3 standard planes.

\section{Tissue Microarray Construction}

From tumor registry databases, patients with formalinfixed, paraffin-embedded schwannoma and control tissues were selected. A total of 188 blocks were selected from 169 patients. Slides were reviewed, and viable areas of tumor were delineated by a soft-tissue sarcoma pathologist (F.L.L.). These areas were manually punched in duplicate with a $1.0-\mathrm{mm}$ core and placed into the recipient TMA block; 121 samples from patients with primary SPSs were included. Control tissues included adjacent histologically normal nerves from patients with schwannoma $(n=11)$. Other control tissues included tumor from patients with NF Type $1(\mathrm{n}=7)$; schwannoma $(\mathrm{n}=1)$; glandular malignant schwannoma $(\mathrm{n}=1)$; neurofibroma $(\mathrm{n}=2)$; MPNST $(\mathrm{n}=3)$; sporadic MPNST $(\mathrm{n}=2)$; NF2 $(\mathrm{n}=6)$; schwannomatosis ( $=5)$; sporadic schwannomas from cranial nerves $(\mathrm{n}=8)$; INI1-negative epithelioid sarcomas $(\mathrm{n}=6)$; INII-positive, unclassified sarcoma with epithelioid features $(\mathrm{n}=1)$; pigmented psammomatous schwannoma $(\mathrm{n}=1)$; melanoma from a patient treated for schwannoma $(\mathrm{n}=1)$; and other benign nerve tumors (neuroma $[\mathrm{n}=1]$, spindle cell tumor with schwannian differentiation [ $\mathrm{n}=1]$, and benign nerve sheath tumor $[\mathrm{n}=2])$. Tumors were recurrent at presentation in 7 patients, and tumor status was not available for 1 sample. No tissue sample was included from any tumor that had been irradiated prior to surgery.

\section{Immunohistochemistry}

Unstained slides were de-paraffinized using standard procedures, and antigen retrieval was achieved using Envision FLEX target retrieval solution (PDGFR- $\beta$ ), citrate buffer (HER-2, survivin), and proteinase K (EGFR). Antibodies were obtained from Santa Cruz (PDGFR- $\beta$, sc-339, 1:50), Thermo Scientific (HER-2, clone e2-4001, 1:300), and Invitrogen (EGFR, clone 31G7, 1:50). Expression of biomarkers was scored by 2 independent observers (A.J.F.L. and G.A.S.). The percentage of tumor cells showing staining and the intensity of staining in the tumor cells on a scale of $0-3$, where 0 represents no staining; 1 , low staining; 2, moderate staining; and 3 , intense staining (see Fig. 2 for results of TMA biomarker expression). Specimens that did not contain sufficient material for scoring were excluded from further analysis.

\section{Statistical Analysis}

The Student 2-tailed t-test was performed to determine the differences in expression of biomarkers as determined using immunohistochemistry. Graphs were constructed using R statistical software.

\section{Results \\ Clinical Database}

Patient Variables

Clinicopathological variables of 291 patients presenting with SPS are summarized in Table 2. Of these, 215 patients were Caucasian (74\%), 38 were Hispanic (13\%), 19 were Asian or Pacific Islander (7\%), 17 were African American (6\%), 1 was Native American (0.3\%), and race was not specified for 1 patient $(0.3 \%)$. Diagnosis was made by histological examination of the tumor after resection, biopsy, or fine needle aspiration. Diagnosis was made based on findings from presurgical biopsy in 150 samples (51\%), fine needle aspiration in 11 samples (4\%), incisional biopsy in 1 $(0.3 \%)$, frozen section in $3(1 \%)$, and postexcision paraffin section in $126(43 \%)$. The chief complaint was not available for 6 patients.

\section{Tumor Variables}

Tumor size was available for 271 patients and was defined as the maximum dimension reported at radiological or pathological assessment, as measurements by both methods were unavailable for all patients. Nonvestibular (noncranial nerve) schwannomas located in the head and neck (10\% of the total) arose from the cervical nerve roots, sympathetic chain, or subcutaneously. A more detailed description of where tumors arose in these locations and the spinal levels affected by schwannoma are described in Table 3 and Fig. 1, respectively. Erosion of adjacent bone was noted in 17 tumors $(6 \%)$. Histologically, SPSs were divided into the following subclasses: $247(85 \%)$ were identified as conventional schwannomas, 37 (13\%) were cellular schwannomas, 6 (2\%) showed ancient or degenerative changes, and $1(0.3 \%)$ was a plexiform schwannoma. Of the cellular schwannomas, 12 (32\%) occurred in the thorax, $11(30 \%)$ in the abdomen/retroperitoneum, 7 (19\%) in the extremities, and 7 (17\%) in the pelvis.

\section{Treatment Variables}

Surgery was the mainstay of treatment, with 232 patients $(80 \%)$ undergoing resection. Of these patients, 214 underwent 1 operation (92\%), 14 underwent 2 (6\%), 2 underwent $3(0.9 \%)$, and 2 patients underwent 4 surgeries $(0.9 \%)$. Blood loss reported as "not significant" or "negligible" was recorded as 0 . Notably, tumors smaller than or equal to the median of $4.7 \mathrm{~cm}$ had a mean blood loss of $251 \mathrm{ml}$, whereas tumors larger than the median had a mean blood loss of $733 \mathrm{ml}$; the difference between the 2 groups was statistically significant $(p=0.00096)$. As most schwannomas are histologically benign tumors, the extent of resection was reported for 164 (71\%) of the 232 patients undergoing surgical extirpation. After resection, surgical margins were either free from tumor (R0) or had tumor present (R1, microscopic tumor present; R2, gross tumor present), as previously defined. ${ }^{20}$ Tumor removal was done en bloc when the tumor arose from a nonfunctional nerve or one with trivial function, and in a subcapsular fashion when nerve sparing was required for functional preservation. 


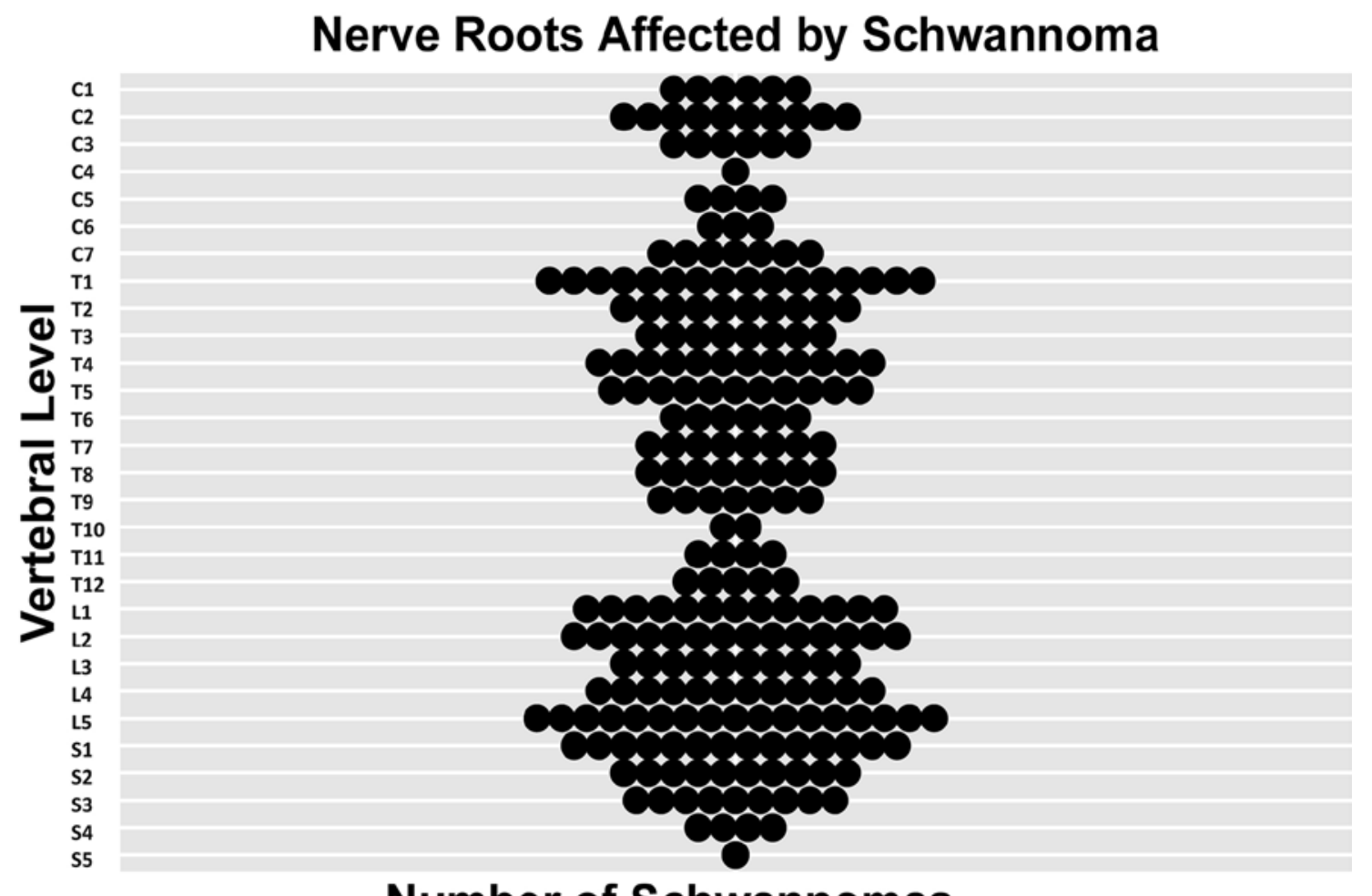

\section{Number of Schwannomas}

FIG. 1. Distribution of the 241 nerves affected by schwannoma for which the spinal level where the tumor occurred was available $(n=128)$, graphed according to spinal level.

Of the 59 patients (20\%) who did not undergo surgery for their disease, justification for this course was provided for 48 of these patients. The decision to delay or forgo surgery was most commonly made because the patient's symptoms were considered tolerable $(n=22,46 \%)$. In 8 patients (17\%) a watch-and-wait approach was chosen. In 8 patients $(17 \%)$ the tumor was in an anatomical location for which surgical exposure was problematic (pelvis, sacrum, tail of pancreas, or rectum) or was abutting or encasing critical vasculature (common iliac artery, aorta, jugular vein, or vena cava). Four patients were considered to have stable disease (8\%), 3 patients declined the recommended procedure (6\%), 2 patients delayed surgery because they did not have insurance (4\%), and 1 patient $(2 \%)$ was too sick to undergo surgery. Of patients who did not undergo surgery, nonsurgical therapy was administered to 3 patients (1\%): 2 patients $(0.7 \%)$ received radiation, and 1 patient $(0.3 \%)$ received chemotherapy (vincristine, dactinomycin, and cyclophosphamide).

\section{Complications}

Surgical complications (Table 4) were defined as any deviation from the normal postoperative course ${ }^{8}$ including asymptomatic complications such as arrhythmia and atelectasis. Data regarding intraoperative complications or complications occurring within 24 hours of surgery were available for 225 patients, of whom 5 (2.2\%) experienced one of the following: injury to the bronchus with chylothorax and pleural effusion, renal vein laceration with hypotension, spleen laceration requiring reoperation, persis- tent venous bleeding delaying closure, and persistent iliac bleeding $(\mathrm{n}=1$ each).

Short-term postoperative (1-29 days postoperatively) complication data (Table 4) were available for $231 \mathrm{pa-}$ tients, of whom $36(16 \%)$ experienced one or more of the following: hemorrhage, arrhythmia, urinary retention, CSF leakage, and respiratory insufficiency $(n=4$ each); ileus $(n=3)$; thrombosis, chylothorax, seroma, pneumonia, and dehiscence leading to reoperation $(\mathrm{n}=2$ each); and anemia requiring transfusion, pseudomeningocele, abscess requiring drainage, and pneumothorax $(\mathrm{n}=1$ each). Follow-up data on long-term complications (more than 30 days postoperatively) were available for 199 patients, of whom 7 (3.5\%) suffered from complications including one or more of the following: incisional hernia and pneumonia $(\mathrm{n}=2$ each); and peritonitis with diverticulum rupture, pleural effusion, vertebral compression fractures requiring kyphoplasty, respiratory insufficiency, DVT, and urinary retention ( $\mathrm{n}=1$ each). Notably, all patients who experienced long-term complications had tumors ranging from 7 to $19 \mathrm{~cm}$ with a mean size of $11.1 \pm 4.2 \mathrm{~cm}$. These tumors occurred in the pelvis $(\mathrm{n}=3,43 \%)$; abdomen ( $\mathrm{n}$ $=2,29 \%)$; and thoracic spine and the thigh $(\mathrm{n}=1$ each, $14 \%)$. Death as a result of treatment occurred in only $1 \mathrm{pa}-$ tient $(0.7 \%)$, who died of respiratory distress due to pneumonia 1 month after surgery.

\section{Follow-Up}

Follow-up data were collected to the most recent date available and are summarized in Table 4. Significantly, tu- 
TABLE 2. Demographic, tumor, and treatment variables of patients with SPSs

\begin{tabular}{|c|c|}
\hline Variable & Value \\
\hline \multicolumn{2}{|l|}{ Age, yrs } \\
\hline Median \pm SD & 50 \\
\hline SD & 16.8 \\
\hline Range & $7-89$ \\
\hline \multicolumn{2}{|l|}{ Sex } \\
\hline $\mathrm{F}$ & $153(52.6)$ \\
\hline M & $138(47.4)$ \\
\hline \multicolumn{2}{|l|}{ Chief complaint } \\
\hline Pain & $161(55.3)$ \\
\hline Paresthesia & $14(4.8)$ \\
\hline Palpated painless mass & $14(4.8)$ \\
\hline Dysesthesia & $10(3.4)$ \\
\hline Weakness/nerve dysfunction & $10(3.4)$ \\
\hline Cough & $8(2.7)$ \\
\hline Respiratory symptoms & $4(1.4)$ \\
\hline Other* & $21(7.2)$ \\
\hline Asymptomatic, incidental finding & $49(16.8)$ \\
\hline \multicolumn{2}{|l|}{ Tumor size† } \\
\hline Mean \pm SD & $5.5 \pm 4.0$ \\
\hline Range & $0.3-26$ \\
\hline \multicolumn{2}{|l|}{ Tumor location } \\
\hline Head \& neck & $28(9.6)$ \\
\hline Extremities & $69(23.7)$ \\
\hline Thorax & $63(21.6)$ \\
\hline Paraspinal & $33(11.3)$ \\
\hline Abdomen/retroperitoneum & $64(22.0)$ \\
\hline Pelvis & $34(11.7)$ \\
\hline \multicolumn{2}{|l|}{ Surgery } \\
\hline Yes & $232(79.7)$ \\
\hline No & $59(20.3)$ \\
\hline \multicolumn{2}{|l|}{ Complete resection $\ddagger$} \\
\hline Yes & $139(84.8)$ \\
\hline No & $25(15.2)$ \\
\hline \multicolumn{2}{|l|}{ Margin status } \\
\hline R0 & $125(89.9)$ \\
\hline $\mathrm{R} 1$ & $14(10.1)$ \\
\hline Mean op duration \pm SD, hrs§ & $3.4 \pm 3.1$ \\
\hline \multicolumn{2}{|l|}{ Blood loss by vol, mlף } \\
\hline$\leq 500$ & $139(75.1)$ \\
\hline$>500$ & $46(24.9)$ \\
\hline \multicolumn{2}{|l|}{ Blood loss per op, mlף } \\
\hline Mean \pm SD & $533.5 \pm 983.7$ \\
\hline Median & 125.0 \\
\hline \multicolumn{2}{|l|}{ Intraop complications** } \\
\hline Yes & $5(2.2)$ \\
\hline No & $220(97.8)$ \\
\hline
\end{tabular}

CONTINUED IN NEXT COLUMN »
» CONTINUED FROM PREVIOUS COLUMN

TABLE 2. Demographic, tumor, and treatment variables of patients with SPSs

$\mathrm{R} 0$ = gross-total resection with microscopically negative margins; R1 = grosstotal resection with microscopically positive margins.

Values are presented as the number of patients (\%) unless stated otherwise.

* Unknown $(n=4)$; constipation $(n=3)$; hematuria $(n=3)$; ataxia $(n=2)$; and

headache, bloody diarrhea, chronic dyspepsia, tonsillitis, weight loss, hemop-

tysis, fatigue, flu symptoms, fever ( $n=1$ each).

† Available for 271 patients.

$\ddagger$ Available for 164 patients

$\S$ Available for 155 patients.

T Available for 185 patients.

** Available for 225 patients.

mors did not recur in any of the 139 patients who underwent complete, gross-total resection (R0, 125 patients; and R1, 14 patients). Progression of disease occurred in 21 (84\%) of 25 patients who received an incomplete (R2, residual gross tumor or debulking) resection. Symptoms were reported at presentation in $184(79 \%)$ of the 232 patients who underwent surgery for schwannoma and in $41(69 \%)$ of the 59 patients who did not undergo surgery. Symptoms persisted without change in 40 patients (98\%) without surgery. No patient who forwent surgery experienced complete resolution of their symptoms, although one of these patients (2.4\%) did report improvement in symptoms.

In symptomatic patients who underwent resection of the schwannoma, the chance and degree of recovery depended on the symptom in question. In those with dysesthesia prior to surgery $(n=10)$, full absence of dysesthesia was achieved in $4(40 \%)$ and partial improvement in 4 (40\%), and 3 patients (30\%) experienced a change in their symptoms from dysesthesia to pain. For those with paresthesia before undergoing surgery for their disease $(\mathrm{n}=$ $12)$, the symptoms cleared completely in 5 (42\%), partially in 4 (33\%), and 3 patients (25\%) experienced an increase in pain from either progression of disease or as sequelae of surgery. The time to recovery varied from 10 days to 5 months and occurred more quickly in the paresthesia group than in patients with dysesthesias. Weakness before surgery $(\mathrm{n}=9)$ improved less readily, with 5 patients $(56 \%)$ reaching normal strength over recovery periods ranging from 1 to 9 months, and 4 (44\%) not showing meaningful recovery of strength. Pain was the most common symptom $(\mathrm{n}=161)$ and it cleared completely in $76 \%$ of patients for whom follow-up data were available more than 6 months after surgery. In those with incomplete improvement in pain $(14 \%)$ a plateau was typically reached no later than 6 months after surgery, and the majority who improved did so within 3 months of surgery. No improvement in pain was seen in $8 \%$, and $5 \%$ of patients were worse. No significant differences in outcome were noted by the most common histological variants (Table 5).

\section{Tissue Microarray}

Clinical characteristics of the 121 patients with primary SPS in the TMA (Table 6) are similar to those in our clinical cohort. Again, the most common site of tumor was the extremities (28\%), although in the TMA more tumors 
TABLE 3. Sites of origin of SPS

\begin{tabular}{lcccccc}
\hline \multirow{2}{*}{ Site } & \multicolumn{7}{c}{ Location } \\
\cline { 2 - 7 } & Head \& Neck & Extremities & Thorax & Paraspinal & Abdomen/Retroperitoneum & Pelvis \\
\hline Paratracheal & 3 & 0 & 0 & 0 & 0 & 0 \\
\hline Spinal nerve root & 14 & 0 & 25 & 31 & 19 & 10 \\
\hline Perivisceral & 1 & 0 & 0 & 0 & 0 & 4 \\
\hline Lung & 0 & 0 & 9 & 0 & 4 & 0 \\
\hline Peripheral nerve $\dagger$ & 3 & 56 & $14 \ddagger$ & 0 & 3 & 2 \\
\hline Autonomic chain & 3 & 0 & 6 & 1 & 4 & 0 \\
\hline Adrenal gland & 0 & 0 & 0 & 0 & 5 & 0 \\
\hline Pancreas & 0 & 0 & 0 & 0 & 19 & 0 \\
\hline Other/NOS & 4 & 13 & 9 & 1 & 7 \\
\hline
\end{tabular}

NOS = not otherwise specified.

* Arising intra- or extradurally: head and neck $(n=6)$, thorax $(n=2)$, paraspinal $(n=16)$, abdomen/retroperitoneum $(n=4)$, and pelvis $(n=1)$. $\dagger$ Arising subcutaneously: head and neck $(n=2)$, extremities $(n=7)$, thorax $(n=1)$, and abdomen/retroperitoneum ( $n=1)$. Arising intramuscularly: extremities $(n=3)$, thorax $(n=5)$, abdomen/retroperitoneum $(n=3)$, and pelvis $(n=1)$.

$\ddagger$ Within the thorax, 5 tumors were extrapleural.

originated from the thorax (27\%) than the abdomen or retroperitoneum (18\%); the reverse was true in the clinical cohort.

Tissue microarray results are presented in Fig. 2. PDGFR- $\beta$ was expressed in the cytoplasm of $69 \%$ of tumor cells at an average intensity of 2.1, which was higher than in MPNSTs and neurofibromas $(1.50, \mathrm{p}=0.0039$; and $1.33, p=0.0070$, respectively). In nerve, $60 \%$ of cells demonstrated cytoplasmic staining with an average intensity of 1.8. HER-2 was moderately expressed with an average of

TABLE 4. Clinical follow-up

\begin{tabular}{cc}
\hline \multicolumn{1}{c}{ Variable } & Value \\
\hline FU, yrs & \\
\hline Mean \pm SD & $4.2 \pm 4.0$ \\
\hline Range & $0.1-18.9$ \\
\hline Local recurrence* $^{*}$ & $0(0)$ \\
\hline Yes & $139(100)$ \\
\hline No & \\
\hline Symptom change† & $96 / 0(52.2 / 0.0)$ \\
\hline Complete resolution & $33 / 1(17.9 / 2.4)$ \\
\hline Improvement & $45 / 40(24.5 / 97.6)$ \\
\hline No change & $10 / 0(5.4 / 0.0)$ \\
\hline Worsened & $36(15.6)$ \\
\hline Short-term complications $\ddagger$ & $195(84.4)$ \\
\hline Yes & $7(3.5)$ \\
\hline No & $192(96.5)$ \\
\hline Long-term complications§ &
\end{tabular}

Values are presented as the number of patients (\%) unless stated otherwise.

* In patients receiving complete $(\mathrm{R} 1 / \mathrm{R} 0)$ resection.

† Presented as the number of patients who underwent surgery $(n=184) /$

patients who did not undergo surgery $(n=41)$.

$\ddagger$ From 1 to 29 days post-operatively; available for 231 patients.

$\S A t \geq 30$ days postoperatively; available for 199 patients.
$31 \%$ of SPS cells staining and an average intensity of 0.91 . By comparison, an average of $20 \%$ of nerve cells showed HER-2 expression with an intensity of 0.8. HER-2 was expressed at higher levels (0.91) in the cytoplasm of SPS than in MPNSTs and neurofibromas $(0.33, \mathrm{p}=0.002$; and $0.33, \mathrm{p}=0.026$, respectively). EGFR was expressed at low levels, with an average of $10 \%$ of tumor cells showing cytoplasmic staining with an average intensity of 0.68 . This was strikingly lower than the percentage of MPNST and neurofibroma cells showing cytoplasmic EGFR expression $(58 \%, \mathrm{p}<0.0001$; and $37 \%, \mathrm{p}=0.007$, respectively). Nerve had stronger EGFR staining than schwannomas, with an average of $25 \%$ of cells showing cytoplasmic staining and an average intensity of 0.75 . Survivin was expressed more highly in SPS than in nerve, with an average of $66 \%$ showing cytoplasmic staining compared with $46 \%$ in nerve $(\mathrm{p}$ $=0.057$ ). Nuclear survivin was expressed in fewer sporadic schwannoma cells than in MPNST cells (24\% and 50\% respectively, $\mathrm{p}=0.018$ ).

\section{Discussion}

While SPSs do not pose the same risks to a patient as malignant tumors, they can enlarge, with pain being the most common reason for patients to seek treatment. Complete resection of SPS prevents tumor recurrence, but symptoms will not improve if the tumor is left untreated. As difficulty of resection increases with tumor size, delaying treatment may lead to excess morbidity. We observed that patients with larger tumors experienced more blood loss during surgery than those with smaller tumors. In addition, the mean tumor size for patients experiencing longterm complications was more than 2 times greater than the overall mean. However, we recognize that a patient's disease may remain stable indefinitely and that surgery itself presents the risk of lasting complications, which must be prudently weighed against potential benefits of resection.

Remarkably, $70 \%$ of patients undergoing gross-total resection reported complete resolution (52\%) or improve- 
TABLE 5. Patient outcomes and tumor size stratified by schwannoma histological variant

\begin{tabular}{|c|c|c|c|c|}
\hline Variable & Conventional Schwannoma & Cellular Schwannoma & Schwannoma w/ Ancient/Degenerative Changes & Plexiform Schwannoma \\
\hline No. of pts & 247 & 37 & 6 & 1 \\
\hline \multicolumn{5}{|l|}{ Op } \\
\hline Yes & $190(76.9)$ & $35(94.6)$ & $6(100)$ & $1(100)$ \\
\hline No & $57(23.1)$ & $2(5.4)$ & $0(0)$ & $0(0)$ \\
\hline \multicolumn{5}{|l|}{ Symptomatic } \\
\hline Yes & $150(78.9)$ & $29(78.4)$ & $5(83.3)$ & $1(100)$ \\
\hline No & $40(21.1)$ & $8(21.6)$ & $1(16.7)$ & $0(0)$ \\
\hline \multicolumn{5}{|l|}{ Symptom change* } \\
\hline Improved & $103(68.7)$ & $21(72.4)$ & $4(80.0)$ & $1(100)$ \\
\hline No change & $38(25.3)$ & $7(24.1)$ & $1(20.0)$ & $0(0)$ \\
\hline Worsened & $9(6)$ & $1(3.4)$ & $0(0)$ & $0(0)$ \\
\hline Mean size $\pm S D, c m$ & $5.1 \pm 3.8 \dagger$ & $7.8 \pm 4.0 \ddagger$ & $6.7 \pm 3.4$ & 6.3 \\
\hline
\end{tabular}

Values are presented as the number of patients (\%) unless stated otherwise.

* Change in symptoms from patients who were symptomatic and received surgery.

$\dagger$ Available for 230 patients.

$\ddagger$ Available for 34 patients.

A

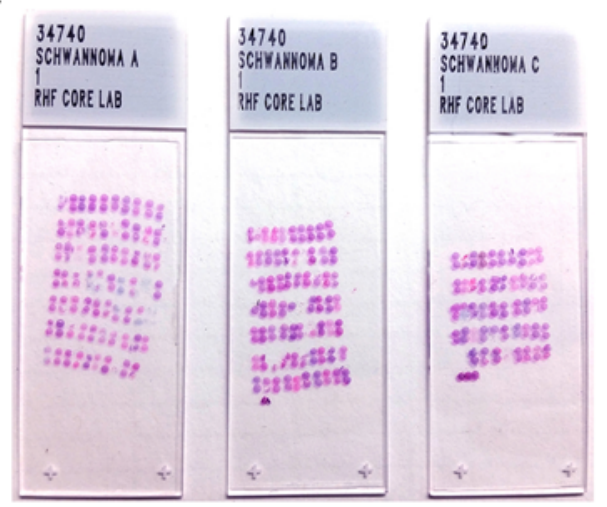

B

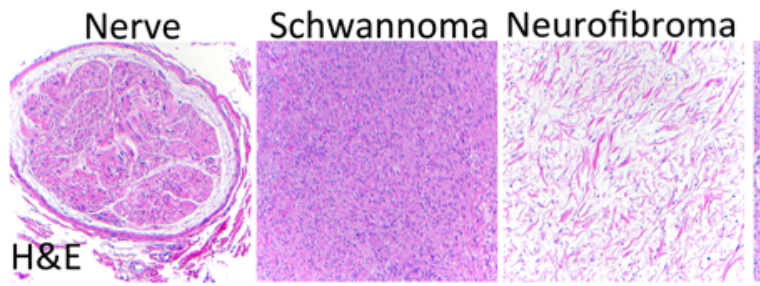

$\mathrm{C}$

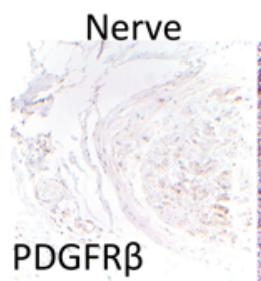

PDGFR $\beta$
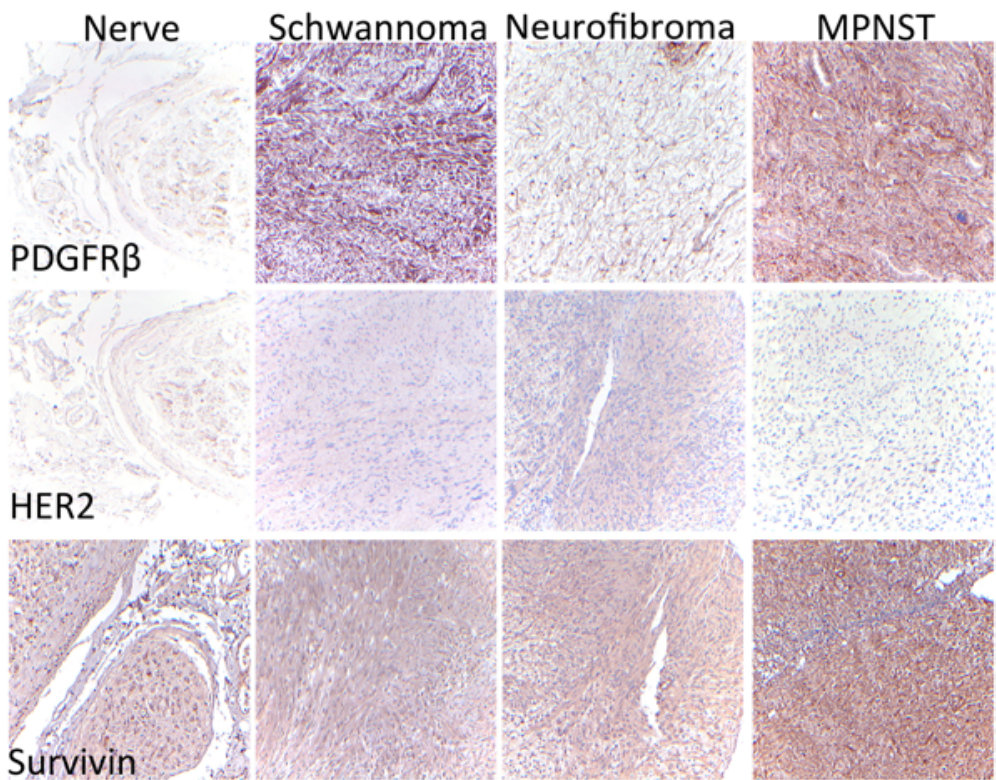

EGFR
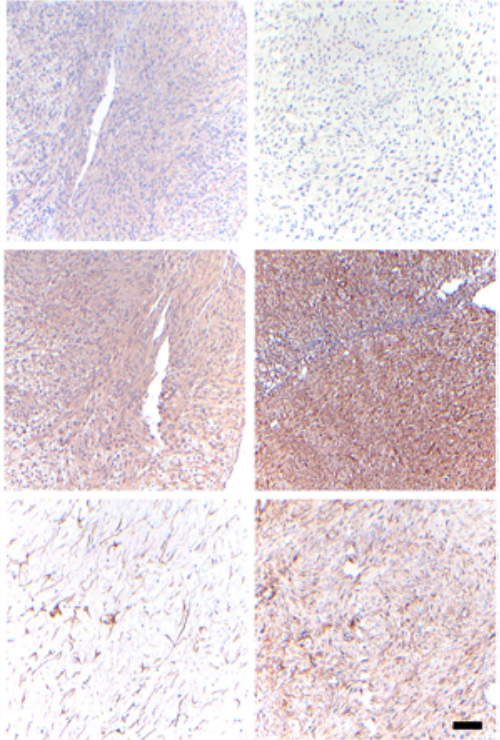

FIG. 2. A: H \& E stain of the tissue microarray. B: Photomicrographs of representative H \& E-stained sections. Bar $=40 \mu \mathrm{m}$. C: Expression of biomarkers in schwannomas, normal nerve, neurofibroma, and MPNST. Bar $=40 \mu \mathrm{m}$. 
TABLE 6. Tissue microarray

\begin{tabular}{cc}
\hline \multicolumn{1}{c}{ Variable } & Value \\
\hline Age, yrs & \\
\hline Median & 48.5 \\
\hline SD & 16.2 \\
\hline Range & $8.6-84.2$ \\
\hline Sex & $64(52.9)$ \\
\hline F & $57(47.1)$ \\
\hline M & \\
\hline Tumor size, cm ${ }^{*}$ & $6.0 \pm 3.8$ \\
\hline Mean \pm SD & $0.6-19.0$ \\
\hline Range & $9(7.4)$ \\
\hline Tumor location & $34(28.1)$ \\
\hline Head \& neck & $33(27.3)$ \\
\hline Extremities & $7(5.8)$ \\
\hline Thorax & $22(18.2)$ \\
\hline Paraspinal & $16(13.2)$ \\
\hline Abdomen/retroperitoneum
\end{tabular}

Values are presented as the number of patients (\%) unless stated otherwise. Data were available for 121 patients except where indicated.

* Tumor size was available for 113 samples.

ment $(18 \%)$ in their symptoms, whereas $98 \%$ of patients who did not undergo surgery reported no improvement during follow-up. This efficacy in reducing symptoms accounts in part for the modest follow-up time in our study (mean 4.2 years), as patients frequently do not return for subsequent appointments. This limitation notwithstanding, studies with fewer patients and longer follow-up times have also shown that gross-total resection prevents tumor recurrence. ${ }^{10}$ Agaram et al. ${ }^{3}$ reported local recurrence in 3 of 6 patients for whom follow-up was available, but they do not comment on the extent of resection, concluding that resection is usually curative for plexiform schwannomas.

Pathology or radiology reports provided measurements of tumor size, as both sources were not available for all patients (e.g., the patient did not undergo surgery). We acknowledge potential discordance between radiological and pathological measurements, but such differences are relatively small (millimeters) in tumors measuring several centimeters. Although we could not detect a worsening of symptoms in patients who did not undergo surgery for their disease, our assessment of the degree of their pain was imperfect because a quantitative assessment of pain at presentation (e.g. " 5 out of 10 on a 1 to 10 scale") was rarely recorded. While this limitation is unlikely to affect conclusions regarding dramatic improvement or worsening of symptoms, incremental changes in pain intensity might have gone undetected.

The clinical and biological features of SPSs reported here are in agreement with previous clinical series, ${ }^{2,3,10,16 \text {, }}$ $22,23,27,31$ demonstrating that SPSs present as painful tumors that most frequently arise in the extremities, abdomen/ retroperitoneum, and thorax. Our series corroborates previous observations in which the proclivity of the cellular schwannoma variant has been described to occur within the thorax and abdomen/retroperitoneum..$^{30}$ SPSs show no significant sex predilection, affect patients across a wide age range, and typically present between the 4th and 6th decades of life. Neither the age at presentation nor the clinical course varies significantly between histological subtypes (i.e., cellular, plexiform, or ancient).

Schwannomas arising in the retroperitoneum and pelvis present challenges to resection, especially considering the degree of exposure required to perform a subcapsular dissection without interrupting functional nerve fibers. Patients in whom resection is especially difficult (e.g., when the tumor is large, hard to reach safely, or close to critical anatomical structures) could benefit from targeted therapy. Inactivation of the NF2 gene has been demonstrated in NF2-associated, ${ }^{21,25}$ sporadic vestibular, ${ }^{28}$ and sporadic spinal ${ }^{11}$ schwannomas. To assess such potential targets, we constructed a TMA of patients with SPSs and show that their clinicopathological features resemble our clinical cohort.

SPSs display a pattern of biomarker expression distinct from that of other peripheral nerve sheath tumors. HER2 and PDGFR- $\beta$ were increased in SPS compared with nerve, and both RTKs are negatively regulated by the NF2 gene product merlin. While expression of HER-2 was primarily cytoplasmic, differing from the classic membranous pattern, others have observed cytoplasmic expression of HER-2 in cancer and speculated as to its role in tumorigenesis. ${ }^{15}$ Nerve samples showed moderate expression of PDGFR- $\beta$, but this result was not entirely unexpected as the peripheral nerve has previously been shown to express PDGFR- $\beta .{ }^{9}$ Consistent with the biology of a benign tumor, SPSs express the antiapoptotic protein survivin at levels intermediate between nerve and MPNSTs, which are known to express high levels of this protein. ${ }^{12}$ In agreement with previous analysis of EGFR expression in vestibular schwannomas, ${ }^{19}$ expression of EGFR was low in our cohort of SPS. However, neurofibromas and MPNSTs expressed high levels of EGFR and lower levels of HER-2 and PDGFR- $\beta$ than SPSs, suggesting markedly different signaling mechanisms driving the tumorigenesis of these tumors. These results are consistent with previous data, albeit our observations in other non-SPS tissues are based on a small sample.

While surgery will remain a mainstay in treatment of SPS, small molecule inhibitors of RTKs and other targeted therapies may soon enter the SPS treatment armamentarium. For example, RTKs targeting PDGFR- $\beta$, such as nilotinib and selumetinib, have been shown to inhibit growth of schwannomas in vitro; ${ }^{5}$ and targeting HER-2 with the monoclonal antibody trastuzumab reduces the growth of schwannoma xenografts from patients with NF2. ${ }^{6}$ Preclinical models are required to assess in vivo efficacy of targeted therapy for SPS, and, given the similar PDGFR- $\beta$ expression we observed between SPS and nerve, potential sensitivity to these agents.

\section{Conclusions}

At present, our data provide a clinicopathological portrait of bona fide SPSs and insights into their biology. Ad- 
vancing our understanding of the unique pathogenesis of SPS will help establish new treatment options for patients, which could alleviate morbidity, especially in those with locally advanced or unresectable disease.

\section{Acknowledgments}

We thank Mr. Paul Cuevas for his assistance in the preparation of this manuscript. Thanks to Mr. Timothy Marquart, Mr. Blake Ebner, and Mr. Joshua Curry for their insight and critical reading of the manuscript.

Funding was received from the following: Texas Neurofibromatosis Foundation (to K. Torres and I. McCutcheon), MD Anderson Physician Scientist Program (to A. J. Lazar), The Sally M. Kingsbury Sarcoma Research Foundation (supporting D. Ingram), and NIH/NCI K08CA160443 (to K. Torres).

\section{References}

1. Abe M, Kawase T, Urano M, Mizoguchi Y, Kuroda M, Kasahara M, et al: Analyses of proliferative potential in schwannomas. Brain Tumor Pathol 17:35-40, 2000

2. Ackerman LV, Taylor FH: Neurogenous tumors within the thorax; a clinicopathological evaluation of forty-eight cases. Cancer 4:669-691, 1951

3. Agaram NP, Prakash S, Antonescu CR: Deep-seated plexiform schwannoma: a pathologic study of 16 cases and comparative analysis with the superficial variety. Am J Surg Pathol 29:1042-1048, 2005

4. Ammoun S, Hanemann CO: Emerging therapeutic targets in schwannomas and other merlin-deficient tumors. Nat Rev Neurol 7:392-399, 2011

5. Ammoun S, Schmid MC, Triner J, Manley P, Hanemann $\mathrm{CO}$ : Nilotinib alone or in combination with selumetinib is a drug candidate for neurofibromatosis type 2 . Neuro Oncol 13:759-766, 2011

6. Clark JJ, Provenzano M, Diggelmann HR, Xu N, Hansen SS, Hansen MR: The ErbB inhibitors trastuzumab and erlotinib inhibit growth of vestibular schwannoma xenografts in nude mice: a preliminary study. Otol Neurotol 29:846-853, 2008

7. Curto M, McClatchey AI: Nf2/Merlin: a coordinator of receptor signalling and intercellular contact. Br J Cancer 98:256-262, 2008

8. Dindo D, Demartines N, Clavien PA: Classification of surgical complications: a new proposal with evaluation in a cohort of 6336 patients and results of a survey. Ann Surg 240:205-213, 2004

9. Eccleston PA, Funa K, Heldin CH: Expression of plateletderived growth factor (PDGF) and PDGF alpha- and betareceptors in the peripheral nervous system: an analysis of sciatic nerve and dorsal root ganglia. Dev Biol 155:459-470, 1993

10. Fletcher CD, Davies SE, McKee PH: Cellular schwannoma: a distinct pseudosarcomatous entity. Histopathology 11:21-35, 1987

11. Fontaine B, Hanson MP, VonSattel JP, Martuza RL, Gusella JF: Loss of chromosome 22 alleles in human sporadic spinal schwannomas. Ann Neurol 29:183-186, 1991

12. Ghadimi MP, Young ED, Belousov R, Zhang Y, Lopez G, Lusby K, et al: Survivin is a viable target for the treatment of malignant peripheral nerve sheath tumors. Clin Cancer Res 18:2545-2557, 2012

13. Gonzalvo A, Fowler A, Cook RJ, Little NS, Wheeler $\mathrm{H}$, McDonald KL, et al: Schwannomatosis, sporadic schwannomatosis, and familial schwannomatosis: a surgical series with long-term follow-up. Clinical article. J Neurosurg 114:756-762, 2011

14. Hanemann CO, Evans DG: News on the genetics, epidemiology, medical care and translational research of schwannomas. J Neurol 253:1533-1541, 2006

15. Horiguchi S, Hishima T, Hayashi Y, Shiozawa Y, Horiguchi $\mathrm{K}$, Kuroi K, et al: HER-2/neu cytoplasmic staining is correlated with neuroendocrine differentiation in breast carcinoma. J Med Dent Sci 57:155-163, 2010

16. Lodding P, Kindblom LG, Angervall L, Stenman G: Cellular schwannoma. A clinicopathologic study of 29 cases. Virchows Arch A Pathol Anat Histopathol 416:237-248, 1990

17. Makni A, Fetirich F, Mbarek M, Ben Safta Z: Presacral schwannoma. J Visc Surg 149:426-427, 2012

18. Murray MR, Stout AP, Bradley CF: Schwann cell versus fibroblast as the origin of the specific nerve sheath tumor: Observations upon normal nerve sheaths and neurilemomas in vitro. Am J Pathol 16:41-60, 1940

19. Prayson RA, Yoder BJ, Barnett GH: Epidermal growth factor receptor is not amplified in schwannomas. Ann Diagn Pathol 11:326-329, 2007

20. Schwab W, Clasen B, Steinhoff HJ: [New and changed guidelines in the TNM system of head and neck tumors.] HNO 35:112-118, 1987 (Ger)

21. Seizinger BR, Martuza RL, Gusella JF: Loss of genes on chromosome 22 in tumorigenesis of human acoustic neuroma. Nature 322:644-647, 1986

22. Stout AP: The peripheral manifestations of the specific nerve sheath tumor (neurilemoma). Am J Cancer 24:751-780, 1935

23. Strauss DC, Qureshi YA, Hayes AJ, Thomas JM: Management of benign retroperitoneal schwannomas: a single-center experience. Am J Surg 202:194-198, 2011

24. Theodosopoulos T, Stafyla VK, Tsiantoula P, Yiallourou A, Marinis A, Kondi-Pafitis A, et al: Special problems encountering surgical management of large retroperitoneal schwannomas. World J Surg Oncol 6:107, 2008

25. Trofatter JA, MacCollin MM, Rutter JL, Murrell JR, Duyao MP, Parry DM, et al: A novel moesin-, ezrin-, radixinlike gene is a candidate for the neurofibromatosis 2 tumor suppressor. Cell 75:826, 1993

26. Verocay J: Zur Kenntnis der "Neurofibrome." Beitr Pathol Anat 48:1-69, 1910

27. Voltaggio L, Murray R, Lasota J, Miettinen M: Gastric schwannoma: a clinicopathologic study of 51 cases and critical review of the literature. Hum Pathol 43:650-659, 2012

28. Welling DB, Guida M, Goll F, Pearl DK, Glasscock ME, Pappas DG, et al: Mutational spectrum in the neurofibromatosis type 2 gene in sporadic and familial schwannomas. Hum Genet 98:189-193, 1996

29. White W, Shiu MH, Rosenblum MK, Erlandson RA, Woodruff JM: Cellular schwannoma. A clinicopathologic study of 57 patients and 58 tumors. Cancer 66:1266-1275, 1990

30. Woodruff JM, Godwin TA, Erlandson RA, Susin M, Martini N: Cellular schwannoma: a variety of schwannoma sometimes mistaken for a malignant tumor. Am J Surg Pathol 5:733-744, 1981

31. Woodruff JM, Marshall ML, Godwin TA, Funkhouser JW, Thompson NJ, Erlandson RA: Plexiform (multinodular) schwannoma. A tumor simulating the plexiform neurofibroma. Am J Surg Pathol 7:691-697, 1983

32. Woodruff JM, Selig AM, Crowley K, Allen PW: Schwannoma (neurilemoma) with malignant transformation. A rare, distinctive peripheral nerve tumor. Am J Surg Pathol 18:882-895, 1994

33. Yi C, Troutman S, Fera D, Stemmer-Rachamimov A, Avila JL, Christian N, et al: A tight junction-associated Merlinangiomotin complex mediates Merlin's regulation of mitogenic signaling and tumor suppressive functions. Cancer Cell 19:527-540, 2011 


\section{Disclosures}

The authors report no conflict of interest concerning the materials or methods used in this study or the findings specified in this paper.

\section{Author Contributions}

Conception and design: McCutcheon, Young, Lazar, Torres, Lev, Pollock. Acquisition of data: McCutcheon, Young, Ingram, Metcalf-Doetsch, Khan, Al Sannaa, Le Loarer, Lazar. Analysis and interpretation of data: McCutcheon, Young, Metcalf-Doetsch,

Khan, Al Sannaa, Le Loarer, Lazar, Slopis, Torres. Drafting the article: McCutcheon, Young, Torres. Critically revising the article: all authors. Reviewed submitted version of manuscript: all authors. Approved the final version of the manuscript on behalf of all authors: McCutcheon. Statistical analysis: Young. Administrative/technical/material support: McCutcheon, Lazar, Torres, Lev, Pollock. Study supervision: McCutcheon, Slopis, Lev.

\section{Correspondence}

Ian E. McCutcheon, Department of Neurosurgery, Division of Surgery, MD Anderson Cancer Center, 1515 Holcombe Blvd., Houston, TX 77030. email: imccutch@mdanderson.org. 